\title{
Jernforbindelser i grundvand - 30 års erfaringer med jernfjernelse
}

\section{Af J C Blandfort, Dansk Geo-servEx a/s.}

Naturen bestemmer, hvilken afjerningsproces vi får i et vandværk, når der ikke tilsættes iltende kemikalier til vandet, som det sker i Danmark. Dette betyder, at jernudfældningerne i de danske vandværksfiltre er at sammenligne med jernhydritudfældninger, der kan findes i naturen udfældet under iltrige forhold.

Tidligere tiders opfattelse af, at jern udfældes som amorf okker i vore filtre, er en sandhed med mange modifikationer, som der skal være klarhed over, når et vandværksfilter skal designes, idet der er forskel på at filtrere amorfe hydroxydflokke og krystallinske jernhydritter. I nærværende artikel er opsamlet 30 års erfaringer omkring det ret "simple" at filtrere jern fra på et vandværksfilter.
Beluftningsinstallation på Robbedale Vandvcerk i Rønne. Billedet viser iltningsprocessen. Der er tydelige jernudfceldninger (antageligvis lepidokrokit). (Foto: Robbedale Vandvcerk)

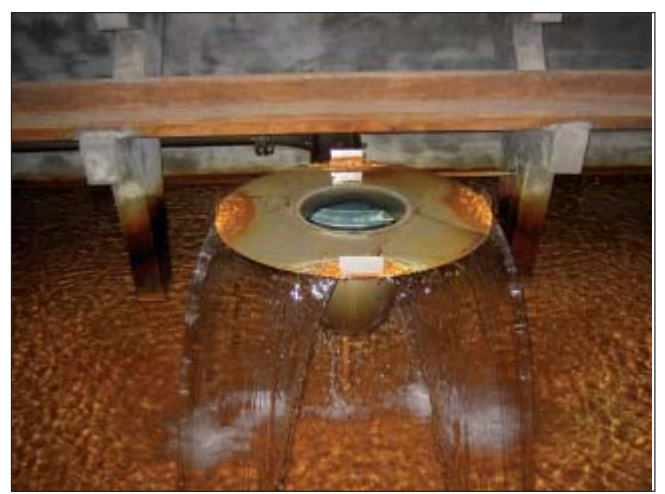

\section{Sandsynlige procesmuligheder}

De mest sandsynlige procesmuligheder, som jeg indtil nu har set i Danmark, er vist i nedenstående tabel. Vi ved heldigvis noget om, hvilken proces - eller meget ofte komlige, når vi studerer råvandsanalysen. "Det forbandede" er imidlertid, at man skal vælge mellem to forskellige filtreringsprincipper bination af processer - der er mest sandsyn-

\begin{tabular}{|c|c|c|c|c|}
\hline Type & Kemisk formel & $\begin{array}{l}\text { Struktur af } \\
\text { udfældning }\end{array}$ & $\begin{array}{l}\text { Størrelse på ud- } \\
\text { fældede partikler }\end{array}$ & Farve \\
\hline $\begin{array}{l}\text { Okker (ferri- } \\
\text { hydrit), kemisk } \\
\text { afjerning }\end{array}$ & $\mathrm{Fe}(\mathrm{OH})_{3}, 3 \mathrm{H}_{2} \mathrm{O}$ & $\begin{array}{l}\text { Amorf } \\
\text { (kompressibel }^{\star} \text { ) }\end{array}$ & Flokke $>20 \mu$ & Gul - orange \\
\hline $\begin{array}{l}\text { Biologisk } \\
\text { afjerning }\end{array}$ & $\begin{array}{l}\mathrm{Fe}(\mathrm{OH})_{3}, 3 \mathrm{H}_{2} \mathrm{O} \\
+ \\
\text { Exopolymer }\end{array}$ & $\begin{array}{l}\text { Amorf til inkom- } \\
\text { pressibel ** }\end{array}$ & $\begin{array}{l}\text { Inkompressible } \\
\text { dele } \\
<5 \mu\end{array}$ & Orange \\
\hline Goethit & $\alpha-\mathrm{FeOOH}$ & $\begin{array}{l}\text { Krystal } \\
\text { (inkompressibel) }\end{array}$ & $<5 \mu$ & Postkasserød \\
\hline Lepidokrokit & $\gamma$-FeOOH & $\begin{array}{l}\text { Krystal } \\
\text { (inkompressibel) }\end{array}$ & $<5 \mu$ & Rød til violet \\
\hline $\begin{array}{c}\text { Siderit } \\
\text { Calciumsiderit }\end{array}$ & $\begin{array}{c}\mathrm{FeCO}_{3} \\
\mathrm{Fe}_{\mathrm{x}} \mathrm{Ca}_{1-\mathrm{x}}\left(\mathrm{CO}_{3}\right)\end{array}$ & $\begin{array}{l}\text { Krystal } \\
\text { (inkompressibel) }\end{array}$ & $<5 \mu$ & $\begin{array}{l}\text { Hvidlig til svag } \\
\text { gullig. } \\
\text { Olivenagtige far- } \\
\text { ver i skyllevand }\end{array}$ \\
\hline Glaukonit *** & $\begin{array}{l}\left(\mathrm{K}, \mathrm{Ca}_{1 / 2}, \mathrm{Na}\right)_{<1}(\mathrm{H} 2 \mathrm{O}) \\
(\mathrm{Al}, \mathrm{Fe}, \mathrm{Mg})_{2} \mathrm{OH}_{2} \\
\mathrm{Al}_{0,2} \mathrm{Si}_{3,8} \mathrm{O}_{10}\end{array}$ & $\begin{array}{l}\text { Krystal } \\
\text { (inkompressibel) }\end{array}$ & $<5 \mu$ & $\begin{array}{l}\text { "Grønsand" i } \\
\text { marine aflejrin- } \\
\text { ger - grøn }\end{array}$ \\
\hline $\begin{array}{l}\text { Katalystisk } \\
\text { afjerning }\end{array}$ & $\left(\mathrm{Fe}_{\mathrm{x}} \mathrm{O}_{\mathrm{y}} \mathrm{H}_{\mathrm{z}}\right)_{\mathrm{n}}$ & $\begin{array}{l}\text { Polymernetværk- } \\
\text { belægninger } \\
\text { (inkompressibel) }\end{array}$ & $\begin{array}{l}\quad>20 \mu \\
\text { Filterkorn bliver } \\
\text { som gule ærter }\end{array}$ & $\begin{array}{l}\text { Gul - kan være } \\
\text { sortplettet af } \\
\text { mangan }\end{array}$ \\
\hline
\end{tabular}

Sandsynlige procesmuligheder. * Kompressibel (sammentrykkelig): Amorfe metalhydroxyder, hvor flokkene kan mishandles (stor mekanisk påvirkning), hvorefter de gendannes. Flokkene har ikke veldefineret størrelse. Normalt koagulationsfiltrering $(d=1,5 \mathrm{~mm})$. ** Inkompressibel: Partiklerne gendannes ikke efter mishandling (mekanisk påvirkning). Partiklerne har veldefinerede størrelser. Normalt screenings-filtrering $(d=0,5 \mathrm{~mm})$.*** Jeg har endnu ikke set glaukonit ved indvinding fra gamle marine aflejringer. (Grafik: UVH efter forfatteren) baseret enten på screening af inkompressible stoffer eller på koaguleringsfiltrering af kompressible stoffer, hvor udfældningen sker ved reversibel dannelse af hydroxydflokke.

\section{Komplekse jernforbindelser}

Komponenter/egenskaber der forstyrrer afjerningsprocessen. Generelt:

- Jernets kemi i vandige opløsninger er spændende og fascinerende, men meget svær at håndtere, idet ferro-jern og ferri-jern er i stand til at danne komplekser, hvilket vil sige, jernet er i stand til at forene sig med mange forskellige ioner under dannelse af nye stabile forbindelser, som totalt ændrer jernforbindelsens kemiske egenskaber.

Det kan forklares på følgende måde. Ferro- og ferri-jernatomet er bundet sammen med 6 molekyler vand (ligander)

Ferro: $\mathrm{Fe}\left(\mathrm{H}_{2} \mathrm{O}\right)_{6}{ }^{++} \quad---\quad$ Ferri: $\mathrm{Fe}\left(\mathrm{H}_{2} \mathrm{O}\right)_{6}^{+++}$

Ved amorf okker $\left(\mathrm{Fe}(\mathrm{OH})_{3}, 3 \mathrm{H}_{2} \mathrm{O}\right)$ er 3 molekyler vand ombyttet med 3 hydroxylioner $\left(\mathrm{OH}^{-}\right)$, hvilket aflader jernatomet og giver et tungtopløseligt produkt med lavt opløselighedsprodukt $\left(10^{-38}\right)$. Goethit har tilsvarende et opløselighedsprodukt på $10^{-42}$.

I kriminalromaner ihjelslås ofrene ofte med blåsyre - cyanid $\left(\mathrm{CN}^{-}\right)$. Når cyanid kombineres med jern på rigtig vis, dannes $\mathrm{Fe}(\mathrm{CN})_{6}^{3-}$, som er ugiftig og har en kompleksitetskonstant (svarer til opløselighedsprodukt) på mindre end $10^{-42}$. Det vil sige, at denne forbindelse ikke kan omdannes til okker under frigivelse af giftige cyanid-ioner.

Naturen er så viselig indrettet, at det normalt er det mest stabile stofkompleks, der går af med sejren og bliver slutproduktet, 
om end det kan gå langsomt set i forhold til et menneskeliv.

I vandforsyningssammenhænge skal man specielt interessere sig for jernkomplekser, som er i ægte opløsning og dermed ikke mulige at filtrere fra, forårsaget af

- Humus - de organiske byggestene i humus samt nedbrydningsprodukter fra humusdannelsen såsom organiske syrer

- Fosfat og kiselsyre

\section{Jernkomplekser og humus}

Humus er ikke en veldefineret kemisk forbindelse. Det består af en lang række byggestene, som kædes sammen af kvælstofatomer på vilkårlig måde, og som giver store molekylkæder.

Humus dannes af den naturlige nedbrydning af død plantevækst, når dette omsættes biologisk af mikrobiologiske svampe og skimmel. De biologisk omsættelige organiske stoffer har som mellemprodukt organiske syrer ( $\mathrm{fx}$ vinsyre, citronsyre og salicylsyre, humussyre), som danner jernkomplekser i kemisk stabile forbindelser.

Denne type jernkomplekser findes normalt i rodzonen, hvor humusdannelsen sker. Den er fundet ved dræning af "overfladevand" til søer og åer forskellig steder på Jorden, men vi ser normalt ikke disse jernkomplekser i dybereliggende grundvandsmagasiner.

Denne jerntype er derfor normalt kun et problem ved overfladevandsbehandling

\section{Jernkomplekset til fosfat}

Dette kan være et problem i særlige tilfælde, hvor der er "højt" fosfatindhold i grundvandet, hvilket somme tider ses ved indvinding fra gammel stenalderhavbund.

Lærebøgernes beskrivelse af stabile fosfatkomplekser med tilhørende "simple" kemiske formler er imidlertid næppe den fulde sandhed. Den dårlige filtreringsevne, der konstateres, skal snarere tilskrives dannelse af et jern-hydroxy-fosfatforbindelse, som ændrer "okkers” flokningsegenskaber i uheldig retning. Fosfat virker "opløsende”

\section{Optimale slam- egenskaber}

Når såkaldt “okker” under iltningsforløbet har et forhold mellem ferro-jern og ferri-jern svarende til magnetjernsten ( $\mathrm{Fe}(\mathrm{II}) \mathrm{Fe}(\mathrm{III})_{2} \mathrm{O}_{4}$ ), bliver hydroxyd-flokkene magnetiske, hvilket giver optimale slamegenskaber, svarende til højeretilbageholdelseskapacitet per filtervolumen. Dette forhold kan udnyttes ved kemisk fældning med ferrosulfat, og formodentlig også hvis man tilsætter ferrosulfat for fjernelse af arsen.

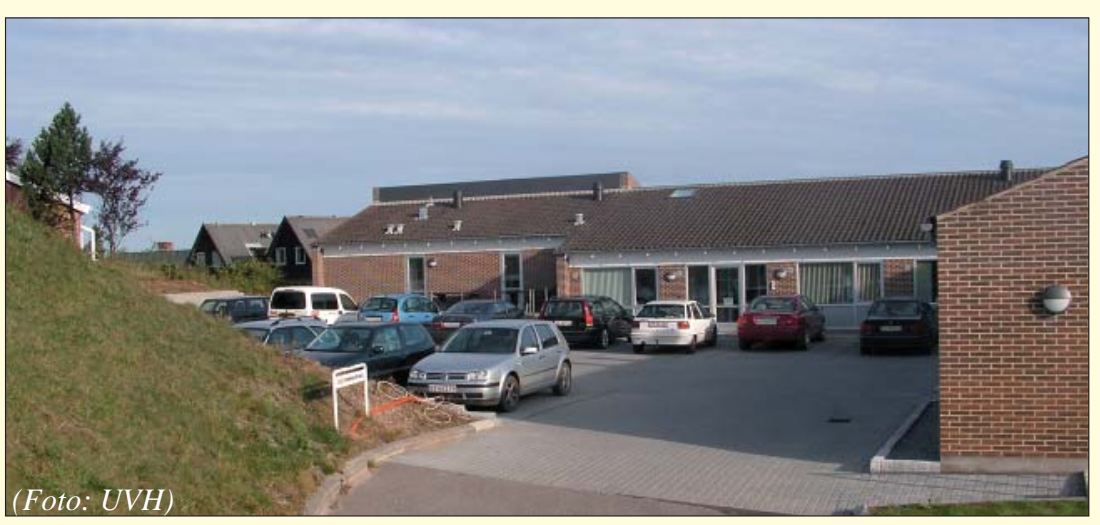

Dansk Geo-servEx a/s, i daglig tale DGE, er et rådgivende firma med hovedkontor i Højbjerg (foto ovenfor) samt lokalkontorer 9 steder i Danmark. Endvidere har DGE afdelinger i Sverige og Litauen.

DGE beskæftiger sig med undersøgelser og oprensning af forurenede grunde, grundvandsundersøgelser, vandværker, bygningsrådgivning mv. DGE har for tiden ansat 75 medarbejdere herunder 65 tekniske specialister/medarbejdere ingeniører, geologer og geofysikere.

DGE er en innovativ virksomhed, hvor medarbejderne er sat i højsædet arbejdende ud fra principperne om frihed under ansvar. og giver små svage flokke, der let sønderdeles igen.

$$
\underset{\mathrm{OH}}{\mathrm{Fe}}-\underset{\mathrm{O}}{\mathrm{O}} \stackrel{\mathrm{O}}{\mathrm{O}}=\mathrm{O}
$$

\section{Jernkomplekset til kiselsyre}

Der kan opregnes tilsvarende for jernkomplekset til kiselsyre, og disse er beskrevet i litteraturen. Jeg har indtil nu ikke set denne kompleksdannelse i dansk grundvand.

\section{“Tommelfingerregler”}

I det følgende skal jeg prøve at opregne “tommelfingerregler" for, hvilken jerntype og dermed afjerningsproces vi kan forvente at finde afhængigt af råvandskvaliteten.

\section{Forudscetning nr. 1:}

Der er normalt følgende 2 yderpunkter for tilstanden af grundvand, som altid er iltfri:

- Reduktiv grundvandstype med indhold af svovlbrinte $\left(\mathrm{H}_{2} \mathrm{~S}\right)$

- Anoxisk grundvandstype med indhold af nitrat $\left(\mathrm{NO}_{3}^{-}\right)$

Indholdet af svovlbrinte hidrører fra biologisk omsætning af organisk stof under forbrug af ilt bundet til sulfat (sulfatreduktion). Herved dannes svovlbrinte, der binder jern op i pyrit $\left(\mathrm{Fe}_{2} \mathrm{~S} / \mathrm{FeS}\right)$. Denne grundvandstype har lavt jernindhold, når grundvandet er i ligevægt.

Indholdet af nitrat hidrører fra biologisk omsætning af naturens kvælstofforbindelser samt fra overgødskning. Når der er nitrat i stabilt grundvand, kan der ikke forekomme svovlbrinte. Nitratindholdet betinger vækst- muligheder for jernbakterier, som binder jernet i “biologisk okker”. Denne grundvandstype har lavt jernindhold, når grundvandet er i ligevægt.

Den naturlige aflejring af jern i grundvandsmagasinet sker som siderit $\left(\mathrm{FeCO}_{3}\right)$ også kaldet jernspat, når der ikke er organisk stof, som kan betinge sulfatreduktion. Der vil i denne grundvandstype være indhold af krystallinsk siderit som følge af forvitring af sideritlagene.

Endelig vil der findes ferro-jern i ægte opløsning med ion-formen $\mathrm{Fe}\left(\mathrm{H}_{2} \mathrm{O}\right)_{6}{ }^{++}$. Indholdets størrelse afhænger af baggrundsniveauet kombineret med, hvor langt fra ligevægten grundvandssystemet er fra en stabil reduktiv tilstand eller en stabil anoxisk tilstand.

Ved grundvandsindvindingen sker der ofte en sammenblanding af forskellige "lokale” typer grundvand, som hver især er i ligevægt, men som ved sammenblandingen kommer i uligevægt. Grundvandsmagasinerne er ofte lagdelte med hensyn til disse ligevægtsegenskaber. Det betyder, at der i praksis kan indvindes grundvand med højt indhold af jern og svovlbrinte og af jern og nitrat.

\section{Forudscetning $n$ r. 2:}

I vandværket iltes grundvandet for at skabe en stabilt aerob (iltrig) tilstand. Grundvandet bliver derfor reaktionsdygtigt, indtil der er indstillet en ny ligevægt, hvor

- Methan er omdannet til $\mathrm{CO}_{2}$

- Svovlforbindelser er omdannet til sulfat

- Kvælstofforbindelser $\left(\mathrm{NH}_{4}^{+}\right)$er omdannet til nitrat

- Ferro-jern er omdannet til ferri-jern

- Mangano-mangan er omdannet til brunsten (Mn(IV)) 
Hvilken af naturens mulige processer, der finder sted, afhænger af proceshastigheden, således at den hurtigst forløbende proces altid sejrer - bliver dominerende.

Hvis mennesket forsøger at gribe ind i naturens processer, går det galt, med mindre man "bedøver" systemet med kraftig kemisk oxidation ( $\mathrm{fx}$ permanganat, chloring etc.)

\section{Procesmuligheder}

Når man analyserer på "okkerslam” for at fastlægge eventuelle jernhydrit-modifikationer, får man oftest ikke et entydigt svar, idet “de videnskabelige undersøgelser" udsiger amorf tilstandsform uden væsentlige spor af krystallinske former. Dette svar kan jeg ikke bruge ved fastlæggelse af filtreringsprocessen.

Derfor er det nødvendigt for mig at opstille et empirisk sæt regler for vurdering af, hvilken jernmodifikation der efter min mening vil dominere afjerningsprocessen. Det samme gør sig gældende ved fejlfinding i processen.

Jeg skal kende farvenuancen af det såkaldte "okkerslam" og dets bundfældningsegenskaber, hvorfor mit besøg på et vandværk altid starter ved skyllevandsbeholderen.

Disse iagttagelser skal så kombineres med følgende muligheder:
Okker (ferrihydrit) kemisk afjerning: Denne jernform er ikke dominerende i nogle af de mulige afjerningsprocesser, med mindre pH-værdien bliver større end 8,2.

Det må imidlertid altid forventes, at en mindre del af jernet udfældes på denne form.

\section{Biologisk afjerning:}

Denne proces er dominerende ved pH-værdier under 7,2.

Processen finder sted ved højere $\mathrm{pH}$ værdier, når vandet har lavt redox-potentiale svarende til, at der er et indhold af methan og/eller svovlbrinte. Den højeste pH-værdi, som processen er observeret ved, er ca. 8,0 - 8,2.

Processen binder det udfældede jern op i bakterieslim (exopolymere), som giver “tungt stabilt slam”, der imidlertid ikke kan reflokkes, såfremt det slås i stykker.

Der findes ret mange typer jernbakterier. I litteraturen er der som oftest kun henvist til Galionella-familien.

\section{Goethit (ikke dominerende):}

Denne type findes sjældent i vandværkssammenhænge. Litteraturen anviser, at krystallinsk siderit $\left(\mathrm{FeCO}_{3}\right)$ kan iltes på fast form til goethit.
Lepidokrokit (dominerende):

Denne type dannes almindeligvis i vand med lav alkalinitet $\left(\mathrm{HCO}_{3}{ }^{-}<200 \mathrm{mg} / \mathrm{l}\right)$. Store indhold af $\mathrm{SiO}_{2}$ forstyrrer måske udfældningen (bryder krystalstrukturen). I litteraturen er der fundet henvisning til, at iltningsproduktet af siderit kan blive lepidokrokit, som jeg i 2004 har set det ske på Skagen Vandværk i forbindelse med forsøg på etablering af pilotanlæg.

Typen er vanskelig at filtrere (partikelfiltrering) og har yderligere den egenskab at skifte elektrisk overfladeladning fra positiv til negativ, når pH-værdien passerer ca. 7,5.

Typen findes normalt ved vandtyper med aggressiv $\mathrm{CO}_{2}$, som så først skal neutraliseres efter jernfjernelsen.

Afjerningsprocessen fordrer, at vandet umiddelbart efter beluftning skal på filtret, således at processen starter i selve filtermatrixen. Hvis ikke dannes der fine krystaller, som ikke kan filtreres. Der kommer belægninger på filtermaterialet.

Siderit, calciumsiderit (ikke dominerende, men stcrkt generende):

Siderit kan normalt ikke dannes i vandværket - men findes i grundvandet ved “åbne” grundvandsmagasiner = godt ydende boringer uden væsentlig sænkning.

Siderit er observeret som en del af jern- 
indholdet, når alkaliniteten er > 150 mg/l $\mathrm{HCO}_{3}{ }^{-}$. Afjerningen sker ved screening $(\mathrm{d}=$ ca. $0,5 \mathrm{~mm}$ )

\section{Katalytisk afjerning:}

Katalytisk afjerning er normalt den dominerende kemiske proces, når alkaliniteten er $>200 \mathrm{mg} / \mathrm{HCO}_{3}^{-}$.

Der kommer hårde, voksende belægninger på filtermaterialet. Meget ofte ses også god mangan-fjernelse sammen med jernfjernelsen. Man skal være varsom med at skifte filtermateriale, selv om man synes, det bliver for grovkornet.

Belægningernes teoretiske kemiske opbygning, hvor der er vist indbygning af mangan, er:

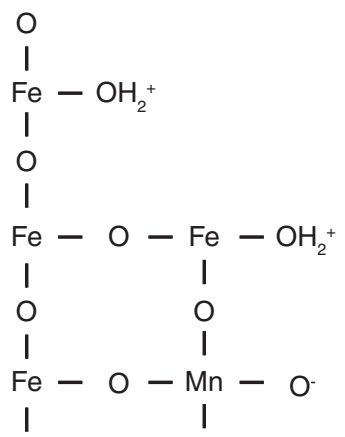

Belægningerne virker som en slags ionbytter ved adsorption af en række uønskede metaller, som kan findes i vandet på baseform som $\mathrm{fx}$

\section{Chromat: $\mathrm{HCrO}_{4}^{-}$}

Arsenat: $\mathrm{HAsO}_{4}^{2-}$

\section{Guideline for mulige jernudfældninger}

De 30 års erfaringer og iagttagelser omkring afjerningsprocesser ved behandling af grundvand på danske vandværker er vist på figuren til højre. Det bemærkes, at grundvandets alkalinitet (indhold af hydrogenkarbonat) spiller en væsentlig rolle, hvor erfaringerne viser, at $200 \mathrm{mg} / \mathrm{l} \mathrm{HCO}_{3}^{-}$er en tærskelværdi med betydning for den kemiske udfældning.

Endvidere har grundvandets redox-potentiale - kombineret med den aktuelle $\mathrm{pH}$ værdi - ret stor indflydelse på, om der sker en biologisk eller kemisk iltning af grundvandets ferro-jern til ferri-jern.

Kvalitetskravet til jernindholdet udpumpet fra danske vandværker er $0,1 \mathrm{mg} / \mathrm{l}$ jern, hvilket kan være vanskelig at overholde forskellige steder med blødt vand i Danmark. Ved brug af denne guideline har vi i DGE indtil nu løst alle problemer med dårlige afjerningsprocesser over alt i Danmark, hvor vandværkerne har bedt om bistand. Erfaringerne er ligeledes benyttet i flere lande overalt på vor klode ved opførelse af nye vandværker, som bygges af visse danske entrepenører.

\section{Normalt forekommende}

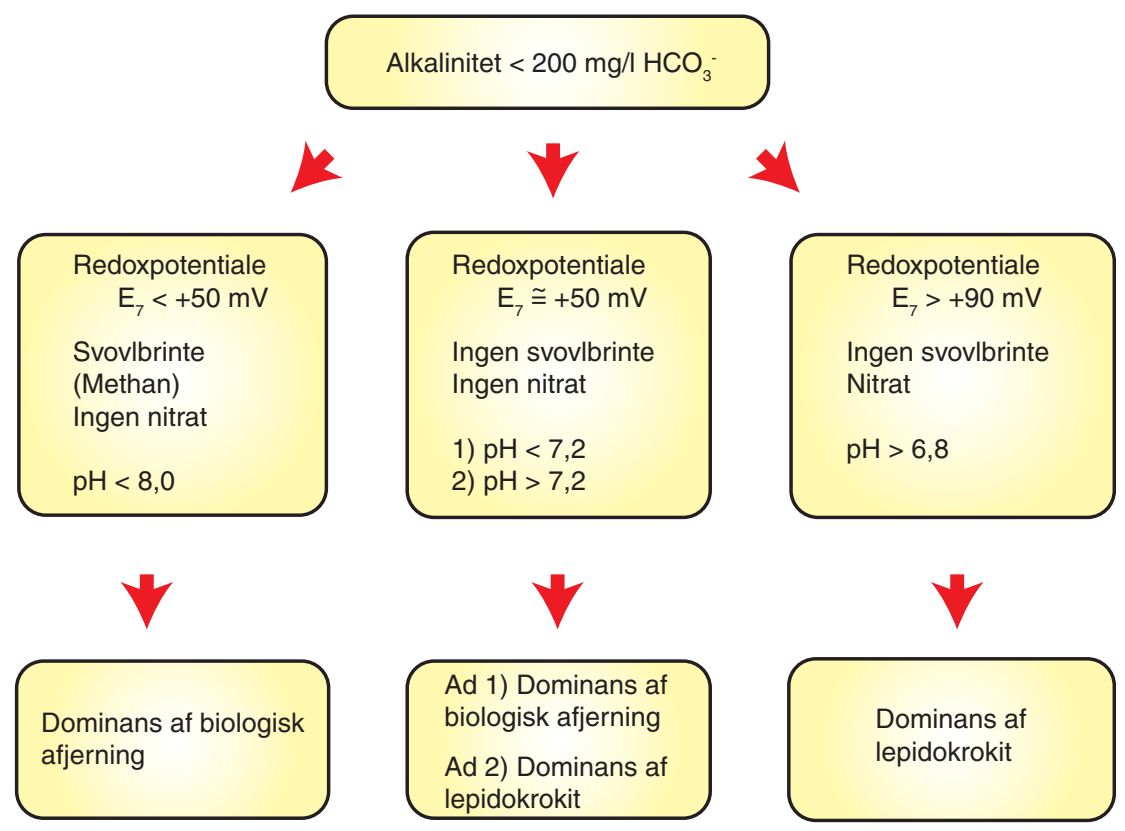

NB!

Alkalinitet: 150 mg/L - 200 mg/ $\mathrm{L} \mathrm{HCO}_{3}$.

Der kan forekomme indhold af siderit $\left(\mathrm{FeCO}_{3}\right)$

Husk: Ingen regel uden undtagelse

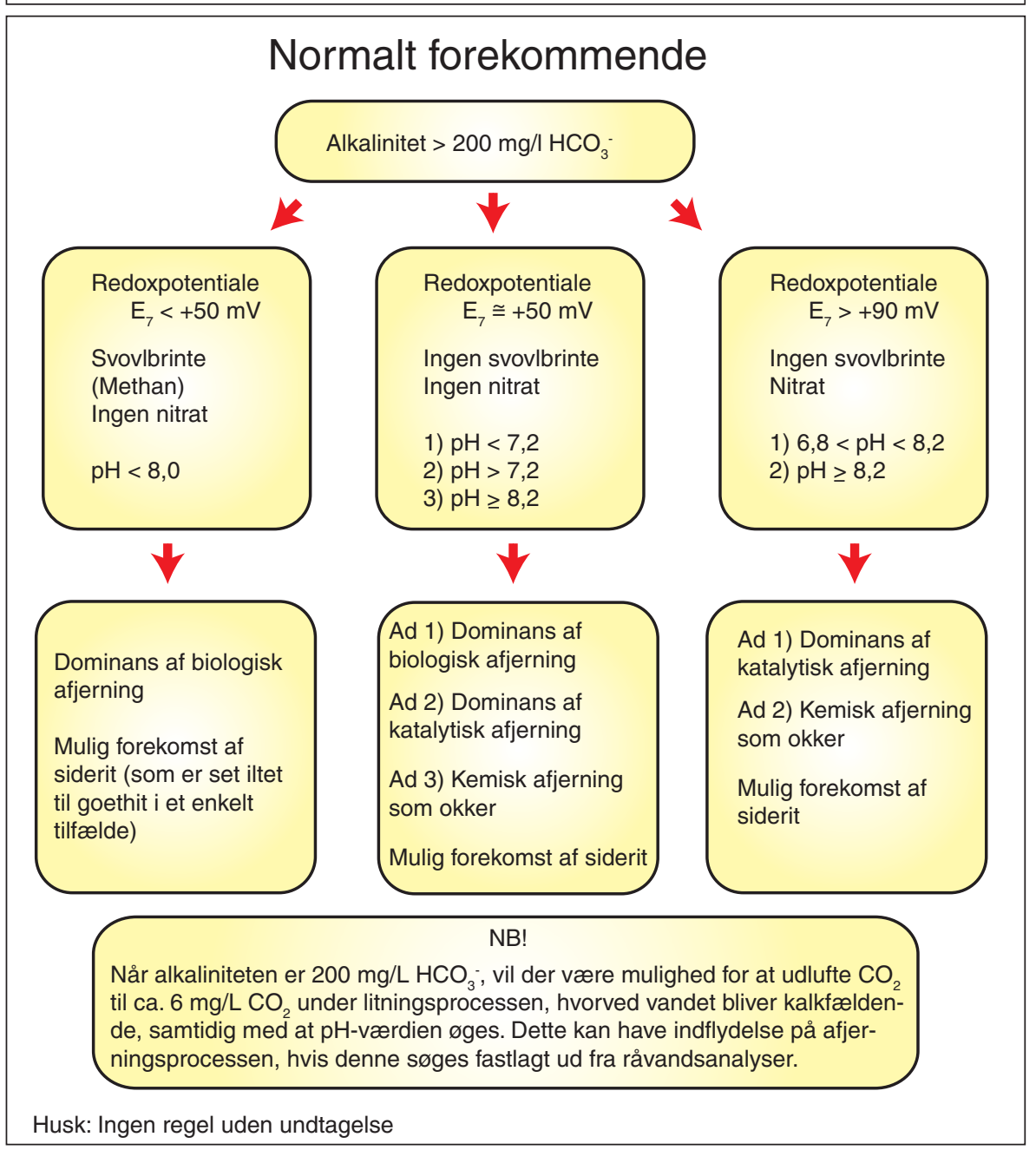

